\title{
Recovery of useful chemicals from palm oil mill wastewater
}

\author{
Yuangsawad Ratanaporn ${ }^{1}$, Na-Ranong Duangkamol, ${ }^{2,}$, Tago Teruoki ${ }^{3}$ and Masuda Takao ${ }^{4}$ \\ ${ }^{1}$ Rajamangala University of Technology Krungthep, Faculty of Engineering, 2, Nanglinchee Rd., \\ Thunmahamek, Satorn, Bangkok 10120, Thailand \\ ${ }^{2}$ King Mongkut's Institute of Technology Ladkrabang, Faculty of Engineering, 1, Chalongkrung 1, \\ Ladkrabang, Bangkok 10520, Thailand \\ ${ }^{3}$ Tokyo Institute of Technology, Graduate School of Science and Engineering, 2-12-1, Ookayama, \\ Meguro-ku, Tokyo 152-8552, Japan \\ ${ }^{4}$ Hokkaido University, Faculty of Engineering, N13W8, Kita-ku, Sapporo, Hokkaido 060-8628, Japan
}

\begin{abstract}
A two-step process consisting of pyrolysis of dried sludge and catalytic upgrading of pyrolysed liquid was proposed. Wastewater from a palm oil mill was separated to solid cake and liquid by filtration. The solid cake was dried and pyrolysed at $773 \mathrm{~K}$. Liquid product obtained from the pyrolysis had two immiscible aqueous and oil phases (PL-A and PL-O). Identification of chemicals in PL-A and PL-O indicated that both phases contained various chemicals with unsaturated bonds, such as carboxylic acids and alcohols, however, most of the chemicals could not be identified. Catalytic upgrading of PL-A and PL-O over $\mathrm{ZrO}_{2} \cdot \mathrm{FeO}_{\mathrm{x}}$ were separately performed using a fixed bed reactor at various conditions, $\mathrm{T}=513-723 \mathrm{~K}$ and mass of catalyst to feed rate $=0.25-10 \mathrm{~h}$. The main components in the liquid products of PL-A upgrading were methanol and acetone whereas they were acetone and phenol in the case of PL-O upgrading. More than $15 \%$ of carbon in raw material was deposited on the catalyst. To reduce the carbon deposition, the used catalyst was treated with air at $823 \mathrm{~K}$. This simple treatment could reasonably regenerate the catalyst only for the case of PL-A catalytic upgrading.
\end{abstract}

\section{Introduction}

In South East Asia countries, palm oil and by-products from palm oil refinery process are mainly used as a feedstock of biodiesel production [1]. Due to high demand of biodiesel as alternative energy, scale of palm oil production has been remarkably increased in the recent years. To produce 1 ton of crude palm oil, about 5-7.50 tons of water is consumed and more than 2.5 tons of wastewater is generated and must be treated before discharging to the environment [2]. Since this wastewater is a brown liquid containing large amount of suspended solids and has high COD and BOD values, a large system is usually installed for biological treatment.

\footnotetext{
*Corresponding author: dnaranong@hotmail.com, duangkamol.na@kmitl.ac.th
} 
$\mathrm{Wu}$ T. Y. et al. [3] reported that the suspended solid in wastewater generated from palm oil mills mainly consisted of macromolecules of several organic compounds, such as protein $(12.75 \%)$, carbohydrate (29.55) and lipid (10.21\%) [3]. Pyrolysis is usually applied to decompose macromolecular compounds to obtain mixtures of small molecules in liquid and gas. The pyrolysed liquid may be used, without further treatment, as fuel in an incinerator. On the other hand, it may be catalytically upgraded to the more stable liquid containing less groups of chemicals and used as an alternative chemical feedstock [4-5]. It should be possible to recover useful chemicals from the palm oil mill wastewater by application of a series of pyrolysis and catalytic upgrading steps.

In this study, a two-step process consisting of the pyrolysis of sludge separated from palm oil mill wastewater and catalytic upgrading of the pyrolysed liquid was proposed and its performance, mainly focused at the catalytic upgrading of the pyrolysed liquid, was investigated. Since iron based catalysts were successfully applied to recover ketones and phenol from palm shell-derived oil and domestic sludge derived black water and the addition of zirconia could improve the stability of this catalyst [6-8], zirconia-iron oxide catalyst $\left(\mathrm{ZrO}_{2} \cdot \mathrm{FeO}_{\mathrm{x}}\right)$ was selected as a candidate for the proposed process. Effects of the operating parameters of the catalytic upgrading, reaction temperature and the ratio of catalyst weight to feed flow rate $(\mathrm{W} / \mathrm{F})$, on the product distribution were investigated. In addition, the reusability of the spent catalyst was also examined.

\section{Experimental}

\subsection{Preparation and characterization of pyrolysed liquid}

Figure 1 shows schematic diagram of overall process for recovering useful chemicals from palm oil mill wastewater. Wastewater was obtained from a palm oil mill located in Chonburi Province, Thailand. It was filtrated through a filter paper in order to obtain solid cake and liquid filtrate. The obtained solid cake was dried at $373 \mathrm{~K}$ overnight and then pyrolysed in a quartz reactor at $773 \mathrm{~K}$ in a flow-through nitrogen atmosphere. Condensable liquid was collected by using a series of three traps immersed in an ice bath. After mixing the liquid trapped in each ice trap, the mixture was settled until it was clearly separated to two layers, aqueous phase at the lower layer and oil phase at upper layer. For further discussion, the pyrolysed liquids (PL) in the aqueous phase and in the oil phase were named as "PL-A" and "PL-O", respectively. The liquid filtrate obtained from the filtration, name as F-water, was used instead of pure water in the reaction test in section 2.3.

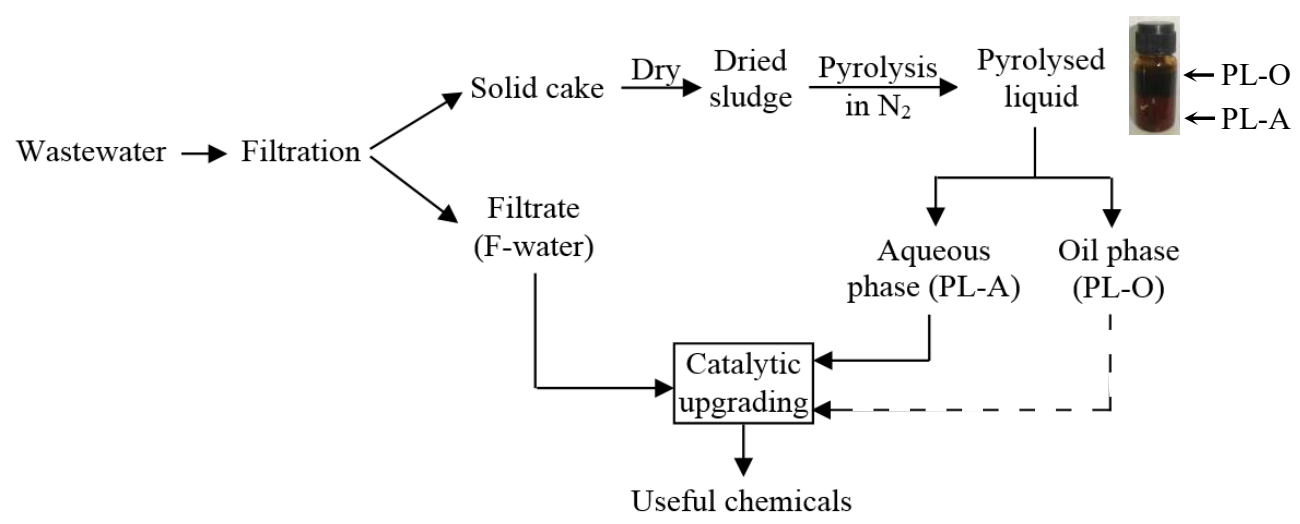

Fig. 1. FTIR functional group of (a) wastewater (b) PL-A and (c) PL-O 
Functional groups of the chemicals in the wastewater, PL-A and PL-O was observed using a Fourier transform infrared spectrometer (FT-IR). Identification of the chemicals in both pyrolysed oil, PL-A and PL-O, was performed using a gas chromatograph equipped with mass spectrometer (GC-MS). Quantifications of the components in PL-A and PL-O were performed using a gas chromatograph equipped with a flame ionization detector (GCFID).

\subsection{Preparation and characterization of zirconia-iron oxide catalyst}

Zirconia-iron oxide catalyst was prepared by co-precipitation technique described in our previous work [8]. $\mathrm{ZrO}\left(\mathrm{NO}_{3}\right)_{2} \cdot 8 \mathrm{H}_{2} \mathrm{O}$ and $\mathrm{Fe}\left(\mathrm{NO}_{3}\right)_{3} \cdot 8 \mathrm{H}_{2} \mathrm{O}$ purchased from Kanto Chemicals (Japan) were used as precursors. $\mathrm{NH}_{3}$ solution (Merck) used as precipitating reagent and was slowly dropped into the continuously stirred solution of the precursors until $\mathrm{pH}$ of the solution reached at 7 . The precipitate was separated from the mixture using vacuum filtration. The obtained solid was dried at $383 \mathrm{~K}$ overnight and then calcined at $773 \mathrm{~K}$ for 4 h. The obtained catalyst, $\mathrm{ZrO}_{2} \cdot \mathrm{FeO}_{\mathrm{x}}$, was ground and sieved to obtain the particle sizes in the range of $300-850 \mu \mathrm{m}$. Crystalline structure of the catalyst was observed using X-ray diffractometer (XRD; Bruker AXS).

\subsection{Catalytic upgrading and reusability test}

The reaction test of each pyrolysed liquid was performed using a fixed bed reactor operated at $1 \mathrm{~atm}$ for $1 \mathrm{~h}$. The pyrolysed liquid and F-water were separately fed to the reactor using a syringe pump. Nitrogen was used as a carrier gas. The outlet of the reactor was connected to a series of two ice traps to collect condensable liquid product. Incondensable product was collected using a gas bag. As for PL-A catalytic upgrading test, PL-A and Fwater were fed to the reactor with the mass ratio of PL-A to F-water $=1: 8$. On the other hand, in the case of PL-O catalytic upgrading test, PL-O was mixed with benzene (PL-O to benzene $=1: 3$ by wt) before being fed to the reactor, the mass ratio of PL-O to F-water was set at $1: 1$. The temperature of the catalytic upgrading was varied from 513-723 $\mathrm{K}$ and the ratio of catalyst weight to feed flow rate (W/F) was varied from 0.25 to $10 \mathrm{~h}$. Quantitative analysis of hydrocarbons in the liquid and gas obtained from the catalytic upgrading was performed using GC-FID. Quantification of inorganic gases, $\mathrm{CO}$ and $\mathrm{CO}_{2}$, was performed using a gas chromatograph equipped with a thermal conductivity detector (GC-TCD).

For the test of catalyst reusability, after the reaction test at $\mathrm{T}=593 \mathrm{~K}, \mathrm{~W} / \mathrm{F}=2 \mathrm{~h}$ using a fresh catalyst was performed for $1 \mathrm{~h}$, air was fed to the reactor at $823 \mathrm{~K}$ for $2 \mathrm{~h}$ in order to regenerate the catalyst. The products obtained from the reaction test using at the fresh and the regenerated catalysts were analysed using GC-FID and GC-TCD.

\section{Results and Discussions}

\subsection{Characterization of wastewater and product from pyrolysis}

Wastewater was separated to solid cake and liquid by filtration. Gravimetrical analysis showed that solid cake $(18.75 \% \mathrm{wt})$ and liquid filtrate $(81.25 \% \mathrm{wt})$ was obtained from the filtration. Pyrolysis of dried solid cake at $773 \mathrm{~K}$ produced char $(34.5 \% \mathrm{wt})$, pyrolised liquid (44.8\%wt) and gas $(20.7 \% \mathrm{wt})$. The pyrolysed oil was then separated to water-soluble fraction, PL-A $(66.74 \% \mathrm{wt})$ and water-insoluble fraction, PL-O $(33.26 \% \mathrm{wt})$. Quantification of carbon content using GC-FID revealed that PL-O had carbon content of $72.78 \% \mathrm{C}$ while PL-A had only $16.04 \%$ of $\mathrm{C}$ in the solution. 
Figure 2 shows FTIR spectra of wastewater, PL-A and PL-O. In spectrum of the wastewater, two peaks were observed. Broad peak at $3300-3600 \mathrm{~cm}^{-1}$ was assigned to $\mathrm{O}-\mathrm{H}$ stretching vibration, indicating water, alcohols and carboxylic acids [9]. Another strong peak around $1500 \mathrm{~cm}^{-1}$ was assigned to $\mathrm{C}=\mathrm{C}$ stretching in aromatics [10]. In addition, the identification using GC-MS showed the presence of pyridine, phenol and derivatives of phenol. As for PL-A, the spectrum also shows broad peak at $3300-3600 \mathrm{~cm}^{-1}$ and it was assigned to the $\mathrm{O}-\mathrm{H}$ stretching vibration of water, alcohols and carboxylic acids. The small peaks in the range of $2800-3000 \mathrm{~cm}^{-1}$ was assigned to $\mathrm{C}-\mathrm{H}$ stretching in saturated hydrocarbons [10]. The peak at $1611 \mathrm{~cm}^{-1}$ was assigned to $\mathrm{C}=\mathrm{O}$ stretching of carboxylic acids, ketones and aldehydes [11]. This result agreed well with GC-MS analysis, where acetic acid, propanoic acid, butanoic acid, hydroxyl acetone and pyrrolidinone were detected. Spectrum of PL-O shows peaks at 2800-3000, 1611, 1400 and $650 \mathrm{~cm}^{-1}$. They were assigned to $\mathrm{C}-\mathrm{H}$ stretching in saturated hydrocarbons, $\mathrm{C}=\mathrm{O}$ stretching of carboxylic acids, ketones and aldehydes, vibrations in $\mathrm{CH}_{2}$ and $\mathrm{CH}_{3}$ groups [11] and $\mathrm{C}-\mathrm{H}$ bending in aromatics, respectively. These chemicals were also detected by GC-MS. Compositions of PL-A and PL-O quantified by GC-FID were summarised in Table 1. In PL-A, only methanol, acetic acid and acetone showed large peak which were calculated easily. Since various peaks with very small area appeared in the chromatogram of PL-A, these were sum as "others-I". Similarly, there are various small peaks appeared in the chromatogram of PL-O and these peaks were sum as "others-II". It should be noted that the components presented in others-I and others-II were different. Due to the difference of chemical and physical properties of PL-A and PL-O, catalytic upgrading tests were separately performed.

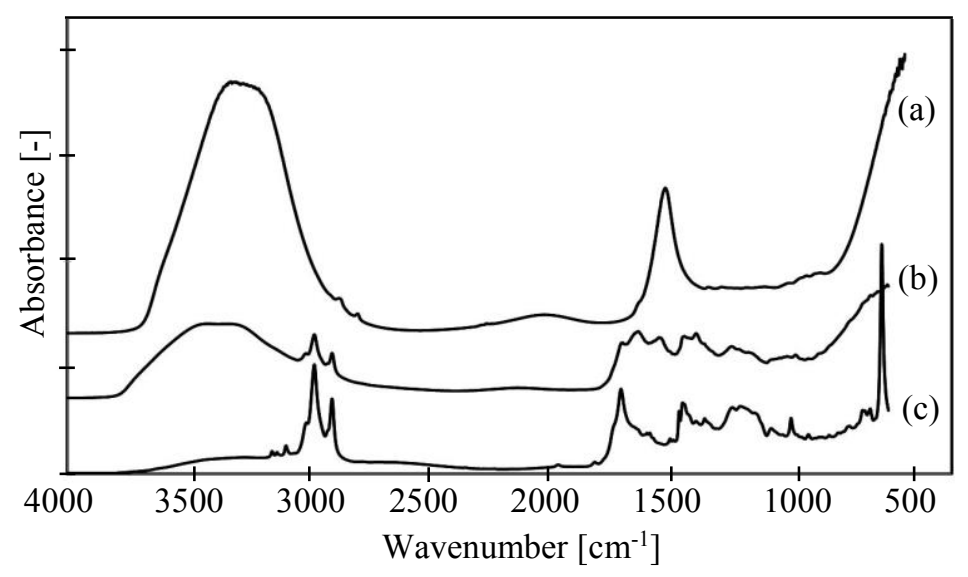

Fig. 2. FTIR spectra of (a) wastewater, (b) PL-A and (c) PL-O

Table 1. Main components in PL-A and PL-O.

\begin{tabular}{|l|c|l|c|}
\hline \multicolumn{2}{|c|}{ PL-A } & \multicolumn{2}{c|}{ PL-O } \\
\hline Component & Composition (\%C) & Component & Composition (\%C) \\
\hline methanol & 6.32 & acetone & 0.39 \\
acetic acid & 27.24 & phenol & 6.60 \\
acetone & 2.40 & m-cresol & 1.85 \\
others-I & 64.04 & others-II & 91.16 \\
\hline
\end{tabular}




\subsection{Catalytic upgrading}

\subsubsection{Catalytic upgrading of PL-A}

Figure 3 shows effect of $\mathrm{W} / \mathrm{F}$ on composition of the product obtained from the catalytic upgrading of PL-A at various temperatures. The catalytic upgrading in this temperature range could reduce the amount of others in PL-A and others were completely removed from $\mathrm{PL}-\mathrm{A}$ at high $\mathrm{W} / \mathrm{F}$, for example at $\mathrm{W} / \mathrm{F}=10 \mathrm{~h}, \mathrm{~T}=583 \mathrm{~K}$. Effect of $\mathrm{W} / \mathrm{F}$ on the amount of acetic acid was similar to the effect of W/F on the amount of others, the amount of acetic acid monotonically decreased when $\mathrm{W} / \mathrm{F}$ was increased and acetic acid was completely removed at high enough $\mathrm{W} / \mathrm{F}$ and $\mathrm{T}$. On the contrary, the amount of acetone increased until it reached the maximum and then it decreased with further increase of W/F. Only the amount of methanol was insignificantly changed due to the catalytic upgrading. At all temperatures, solid residue and gas were the main products obtained from the reaction of PL-A. It should be noted that the quantification analysis revealed that $\mathrm{CO}_{2}$ was the main composition in the gas product. The dependences of acetic acid, acetone and gas on W/F implied that acetone is produced from the decomposition of acetic acid and further goes to complete oxidation at high $\mathrm{W} / \mathrm{F}$ and $\mathrm{T}$. This behaviour was supported by the mechanism reported in the previous work, acetic acid can be directly converted to acetone and $\mathrm{CO}_{2}$ over $\mathrm{ZrO}_{2} \cdot \mathrm{FeO}_{\mathrm{x}}$ [13]. The highest yield of acetone was obtained at $\mathrm{W} / \mathrm{F}=2 \mathrm{~h}$ and $\mathrm{T}=593 \mathrm{~K}$. To obtain the highest purity of acetone in the liquid product $(>95 \%)$, the catalytic upgrading at $\mathrm{W} / \mathrm{F}=6 \mathrm{~h}$ and $\mathrm{T}=593 \mathrm{~K}$ is suggested. Since large amount of carbon deposited on the catalyst, regeneration of the used catalyst was further investigated in section 3.3 .
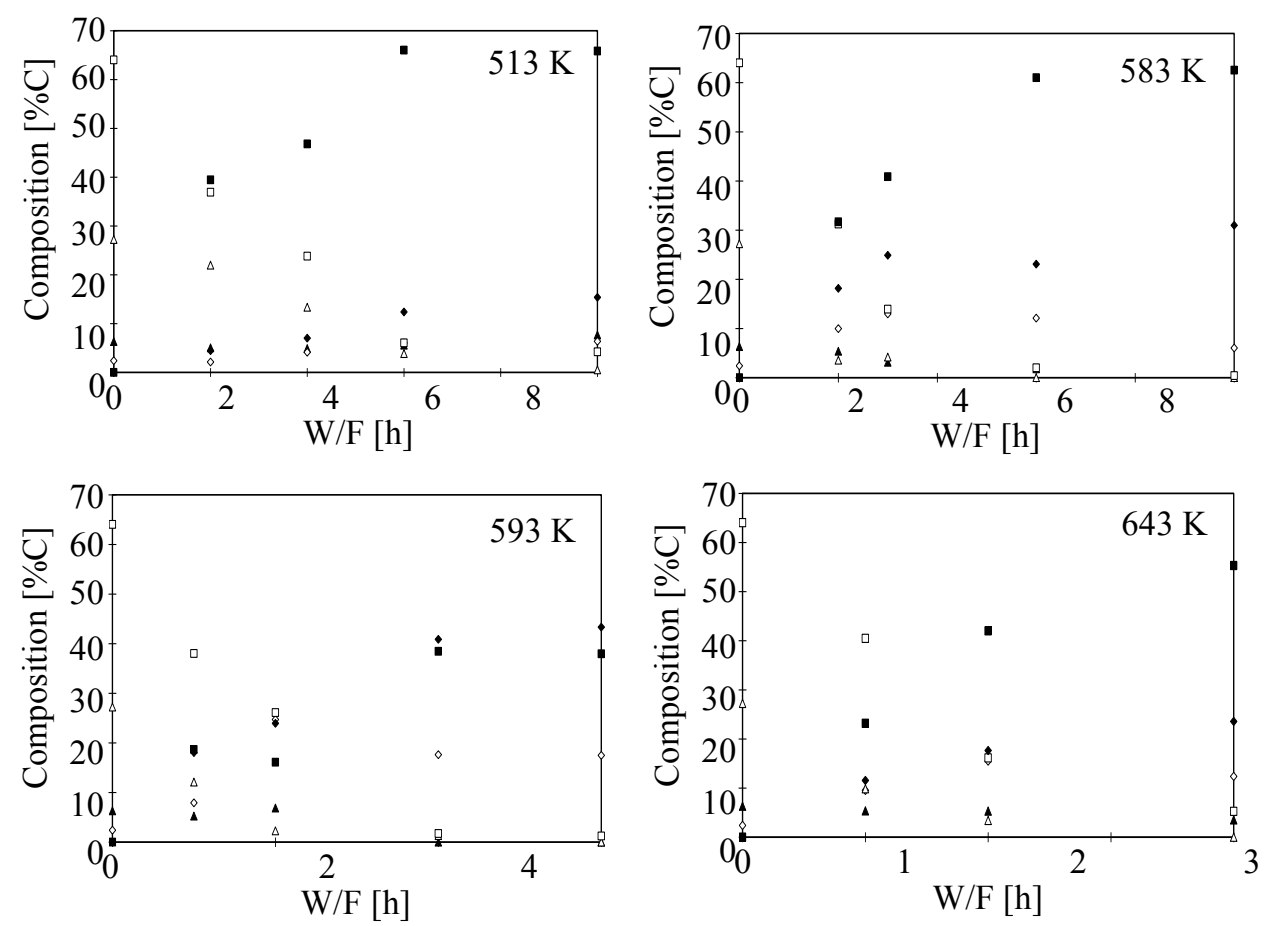

Fig. 3. Effect of $\mathrm{W} / \mathrm{F}$ on product composition obtained from catalytic upgrading of PL-A

$(\boldsymbol{\Delta}$ : methanol, $\diamond:$ acetone, $\Delta$ : acetic acid, $\square$ : others in liquid, $\diamond:$ gas, $\square:$ solid residue) 


\subsubsection{Catalytic upgrading of $P L-O$}

The solid cake obtained from the filtration of palm oil mill wastewater should consist of small debris of fibre and shell. As reported in the previous work [6], acetic acid, methanol, acetone, phenol and cresols were successfully recovered from palm shell derived pyrolysed oil. Although almost all of chemicals in PL-O were not able to identify and the amount of these unidentified compounds was as high as $91.16 \%$, the chemicals should be originated from lignin, hemicellulose and cellulose, which are similar to the case of palm shell derived pyrolysed oil. Therefore, the performance of $\mathrm{ZrO}_{2} \cdot \mathrm{FeO}_{\mathrm{x}}$ on PL-O upgrading was focused on the formation of acetic acid, methanol, acetone, phenol and cresols.

Figure 4 shows that the amounts of acetone, phenol and m-cresol were slightly affected by the catalytic upgrading. The amounts of acetone and phenol reached their maximum and then decreased with $\mathrm{W} / \mathrm{F}$. As temperature was increased, the maximum yields of acetone and phenol shifted to the lower W/F. Although the highest yield of phenol $(19 \% \mathrm{C})$ was obtained at $\mathrm{W} / \mathrm{F}=0.25 \mathrm{~h}, \mathrm{~T}=723 \mathrm{~K}$, the amount of others in liquid product was high. As for acetic acid and methanol, they were not detected in the products at all conditions. The amounts of others, solid residue and gas were significantly affected by the catalytic upgrading. The amount of solid residue increased with the increase of W/F. At the same $\mathrm{W} / \mathrm{F}$, the amount of solid residue at the lower temperature was less than the amount of solid residue obtained at the higher temperature. For example, at $\mathrm{W} / \mathrm{F}=6 \mathrm{~h}$, the amount of solid residue reduced from $45 \% \mathrm{C}$ to $38 \% \mathrm{C}$ when temperature was increased from 593 to $693 \mathrm{~K}$. This effect was considered as a result of rapid rate of $\mathrm{CO}_{2}$ formation from the oxidation of solid residue at high temperature.
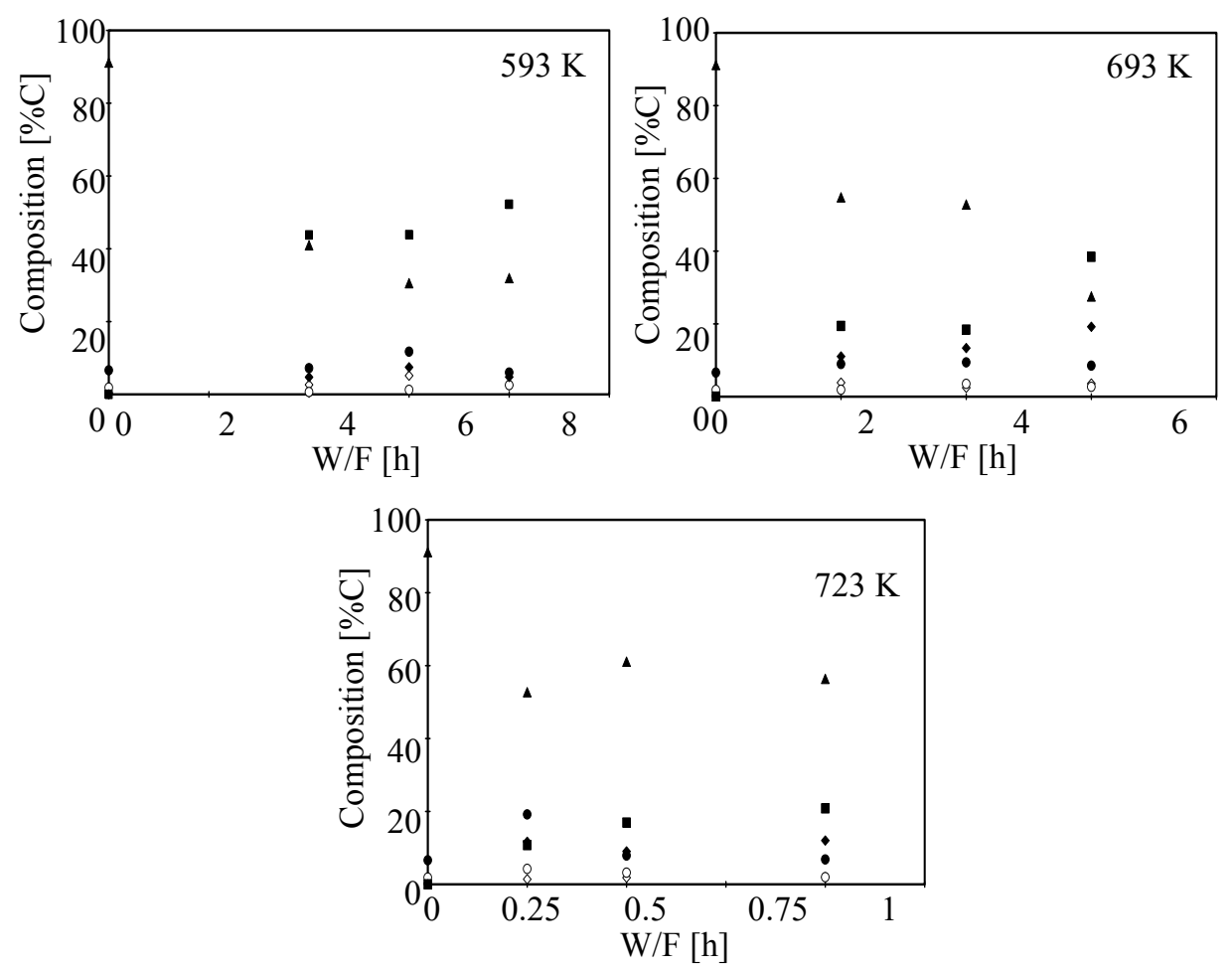

Fig. 4. Effect of W/F on product composition obtained from catalytic upgrading of PL-O (०: m-cresol, $\mathbf{\bullet}$ : phenol, $\diamond:$ acetone, $\mathbf{\Lambda}$ : others in liquid, 


\subsubsection{Conditions for upgrading of PL-A and PL-O}

Based on the experimental results in sections 3.2.1 and 3.2.2, effects of $\mathrm{T}$ and $\mathrm{W} / \mathrm{F}$ on product distribution of PL-A and PL-O upgrading were analyzed. The conditions those provided the highest total amount of the target compounds were $\mathrm{T}=593 \mathrm{~K}, \mathrm{~W} / \mathrm{F}=2 \mathrm{~h}$ for $\mathrm{PL}-\mathrm{A}$ and $\mathrm{T}=593 \mathrm{~K}, \mathrm{~W} / \mathrm{F}=5 \mathrm{~h}$ for PL-O. The predicted compositions of the products obtained from PL-A and PL-O upgrading were summarized in Table 2.

Table 2. The main product obtained from the optimum condition of the reaction.

\begin{tabular}{|l|c|c|}
\hline \multirow{2}{*}{ Component } & \multicolumn{2}{|c|}{ Composition (\%C) } \\
\cline { 2 - 3 } & PL-A & PL-O \\
\hline Methanol & 6.88 & - \\
Acetone & 24.71 & 5.15 \\
Acetic acid & 2.27 & - \\
Phenol & - & 11.74 \\
m-cresol & - & 1.23 \\
others in liquid & 26.11 & 30.56 \\
gas & 23.93 & 7.44 \\
residue & 16.10 & 43.88 \\
\hline
\end{tabular}

\subsection{Catalyst regeneration}

Figure 5 shows XRD patterns of the fresh $\mathrm{ZrO}_{2} \cdot \mathrm{FeO}_{\mathrm{x}}$ and the $\mathrm{ZrO}_{2} \cdot \mathrm{FeO}_{\mathrm{x}}$ after using for catalytic upgrading of PL-A. In both spectra, pattern of hematite structure was observed. These results implied that $\mathrm{FeO}_{\mathrm{x}}$ in the catalyst had hematite structure and this crystalline structure was stable under the reaction condition. In order to study the reusability of catalyst, the used $\mathrm{ZrO}_{2} \cdot \mathrm{FeO}_{\mathrm{x}}$ was regenerated by treating with air $823 \mathrm{~K}$ for $2 \mathrm{~h}$. Products obtained from the catalytic upgrading of PL-A using the fresh and the first cycle regenerated catalysts were compared in Figure 6. The yield of acetone obtained from the reaction over the regenerated catalyst was slightly lower than that of the fresh catalyst. The yield of acetone decreased from $25 \% \mathrm{C}$ to $20 \% \mathrm{C}$ whereas the amount of methanol remains constant at about $10 \% \mathrm{C}$. The reaction over regenerated $\mathrm{ZrO}_{2} \cdot \mathrm{FeO}_{\mathrm{x}}$ produce more solid residue, comparing the reaction over the fresh catalyst.

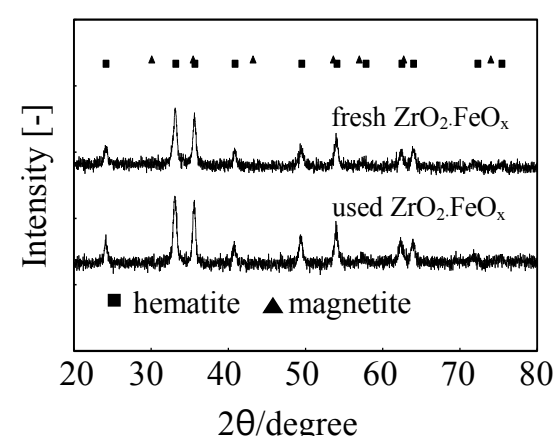

Fig.5. XRD patterns of fresh and used catalysts

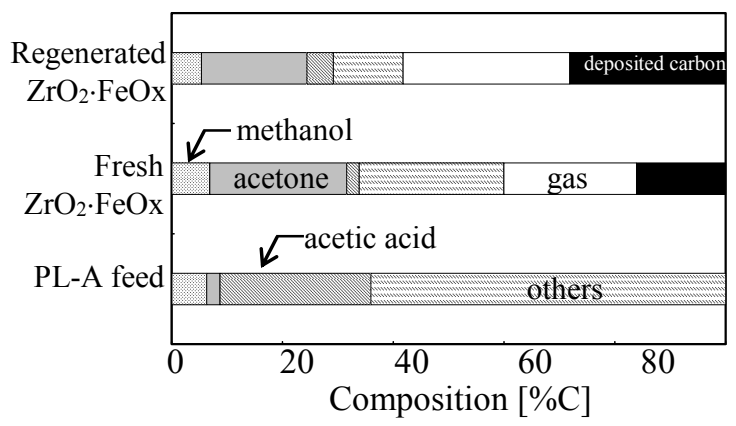

Fig.6. Product distributions obtained from catalytic upgrading of PL-A with fresh and regenerated catalysts $(T=593 \mathrm{~K}, \mathrm{~W} / \mathrm{F}=2 \mathrm{~h})$ 


\section{Conclusions}

A two-step process, consisting of pyrolysis of dried sludge and catalytic upgrading of pyrolysed liquid (PL), was applied to recover methanol, acetone, acetic acid, phenol and mcresol from palm oil mill wastewater. Since PL obtained from the pyrolysis was easily separated to aqueous and oil phases, the catalytic upgrading of each phase was performed using $\mathrm{ZrO}_{2} \cdot \mathrm{FeO}_{\mathrm{x}}$, separately. Investigation of effect of operating condition (temperature (T) and ratio of catalyst weight to feed flow rate $(\mathrm{W} / \mathrm{F})$ ) on product distribution revealed that the highest yields of target compounds were obtained at $\mathrm{T}=593 \mathrm{~K}, \mathrm{~W} / \mathrm{F}=2 \mathrm{~h}$ for PL-A and at $\mathrm{T}=593 \mathrm{~K}, \mathrm{~W} / \mathrm{F}=5 \mathrm{~h}$ for PL-O. At the optimum condition of PL-A upgrading, the yields of methanol, acetone and acetic acid were $6.88,24.71$ and $2.27 \% \mathrm{C}$, respectively. On the other hand, acetone $(5.15 \% \mathrm{C})$, phenol $(11.74 \% \mathrm{C})$ and $\mathrm{m}$-cresol $(1.23 \% \mathrm{C})$ were recovered from PL-O at its optimum condition. Although carbon deposition on the catalyst was severe, the activity of the catalyst was reasonably recovered by oxidation with air at $823 \mathrm{~K}$.

\section{Nomenclatures}

F mass flow rate of PL-A or PL-O $(\mathrm{g} / \mathrm{h})$

W weight of catalyst (g)

\section{Acknowledgement}

Financial supports by Thailand Research Fund and King Mongkut's Institute of Technology Ladkrabang are gratefully acknowledged.

\section{References}

1. D. Sheil, A. Casson, E. Meijaard, M. V. Noordwijk, J. Gaskell, J.Sunderland-Groves, K. Wertz, M. Kanninen, The impacts and opportunities of oil palm in Southeast Asia (CIFOR, Bogor Barat, 2009)

2. S. A. Muyibi, T. Tajari, M. S. Jami, M. K. Amosa, Adv. Environ. Biol., 8(3), 590 (2014)

3. T. Y. Wu, A. W. Mohammad, J. Md. Jahim, N. Anuar, Biotechnol. Adv., 27, 40 (2009)

4. Y. Kim, W. Parker, Bioresour. Technol., 99 , 1409 (2008)

5. S. Yaman, Energ. Convers. Manage., 45, 651 (2004)

6. D. Na-Ranong, R. Yuangsawad, T. Tago, T. Masuda, Korean J. Chem. Eng., 25, 426 (2008)

7. T.Masuda, Y. Kondo, M. Miwa, T. Shimotori, S.R. Mukai, K. Hashimoto, M. Takano, S. Kawasaki, S. Yoshida, Chem. Eng. Sci., 56, 897 (2001)

8. E. Fumoto, Y. Mitzutani, T. Tago, T. Masuda, Appl. Catal. B: Env., 68, 154 (2006)

9. R. O. Arazo, D. A. D. Genuino, M. D. G. de Luna, S. C. Capareda, Sustain. Environ. Res., 27, 7 (2017)

10. B. B. Krishna, B. Biswas, P. Ohri, J. Kumar, R. Singh, Renew. Energ., 98, 238 (2016)

11. J. Alvarez, G. Lopez, M. Amutio, M. Artexe, I. Barbarias, A. Arregi, J. Bilbao, M. Olazar, Fuel Process Technol., 149, 169 (2016)

12. M. B. Valenzuela, C.W. Jones, P. K. Agrawal, Energy Fuels, 20, 1744 (2006)

13. S. Funai, T. Tago, T. Masuda, Catal. Today, 164, 443 (2010) 